\title{
A meta-analysis on the efficacy and safety of St John's wort extract in depression therapy in comparison with selective serotonin reuptake inhibitors in adults
}

\author{
This article was published in the following Dove Press journal: \\ Neuropsychiatric Disease and Treatment \\ II July 2016 \\ Number of times this article has been viewed
}

\author{
Yong-hua Cui' \\ Yi Zheng ${ }^{1,2}$ \\ 'Department of Pediatrics, Beijing \\ An'ding Hospital, Capital Medical \\ University, Beijing, People's Republic \\ of China; ${ }^{2}$ Beijing Institutes of Brain \\ Disorders, Beijing, People's Republic \\ of China
}

Objective: The aim of the study was to investigate the efficacy and safety of St John's wort extract and selective serotonin reuptake inhibitors (SSRIs) in the treatment of depression.

Methods: Databases were searched for studies comparing efficacy and/or safety of St John's wort extract with SSRIs in depression from 1966 to April 2015. Stata software was used for statistical analysis.

Results: Twenty-seven studies met the study entry criteria. A total of 3,126 patients with depression were included. St John's wort extract did not differ from SSRIs in clinical response, remission, and mean reduction in Hamilton Rating Scale for Depression score. St John's wort extract had a significantly lower rate of adverse events compared to SSRIs (summary relative risk: 0.77; $95 \%$ confidence interval: $0.70,0.84, P=0.00$ ) and had fewer withdrawals due to adverse events. St John's wort extract had superior safety in the management of patients with depression.

Conclusion: Both St John's wort extract and SSRIs are effective in treating mild-to-moderate depression. St John's wort extract is safer than SSRIs.

Keywords: St John's wort, selective serotonin reuptake inhibitors, depression, meta-analysis

\section{Introduction}

According to "the World Health Report 2001" by the World Health Organization, approximately one in ten persons suffer from depression globally, and depression is expected to become the second most common disease after coronary heart disease in 2020 . The incidence of depression in the People's Republic of China is estimated at $5 \%-6 \%$ of the population $^{1}$ compared to $15.4 \%$ in the $\mathrm{US}^{2}$ and $27 \%$ in European countries. ${ }^{3}$ The total number of depression patients in the People's Republic of China has reached 90 million $^{1}$ and continues to rise, compromising the health of the general population. Depression has a long treatment cycle period, slow efficacy of medications, and high recurrence rate.

Fluoxetine, paroxetine, sertraline, citalopram, escitalopram, and fluvoxamine are the most commonly used selective serotonin reuptake inhibitors (SSRIs) for treatment of major depression. However, these antidepressants may cause multiple side effects, such as nausea, insomnia, and sexual dysfunction. ${ }^{4}$ Thirty-eight percent of patients with long-term use of SSRIs have experienced at least one side effect, with sexual dysfunction, sleepiness, and weight gain being the most common. ${ }^{5}$

Well-defined extracts from St John's wort (Hypericum perforatum), namely, St John's wort extract (Neurostan), have been used to treat depression for more than a 100 years 
in Germany. Significant efficacy and safety have been demonstrated in animal studies and clinical trials. ${ }^{6,7}$ St John's wort has better antidepressant efficacy than placebo $^{8-10}$ and lower rates of side effects than conventional antidepressants. ${ }^{11,12}$ The use of St John's wort extract for patients with depression, however, remains somewhat controversial, since some studies showed no significant difference in efficacy and safety between St John's wort extract and conventional SSRIs. ${ }^{1-15}$ Given that depression often requires rapid, timely, and prolonged treatment, we should consider not only the effectiveness but also safety of the treatment. Therefore, based on the meta-analysis by Rahimi et al, ${ }^{16}$ which covers literature from 1966 to June 2008, we collected published randomized, controlled clinical trials comparing the efficacy and safety of St John's wort extract and SSRIs from June 2008 to April 2015. In addition, we included similar studies that have been published since 1966 in the People's Republic of China to conduct a comprehensive and objective update on the use of St John's wort extract as an alternative to SSRIs.

\section{Materials and methods \\ Data sources}

The search terms were "St John's wort" or "hypericum" or "Neurostan" and "fluoxetine" or "paroxetine" or "citalopram" or "sertraline" or "escitalopram" or "fluvoxamine" and "depression." PubMed, Cochrane Central Register of Controlled Trials, and Ovid Technologies were searched from June 2008 to April 2015, and China Biology Medicine disc, WanFang Data, and China National Knowledge Infrastructure were searched from 1966 to April 2015.

\section{Study selection}

We searched for studies of treatment of depression with St John's wort extract with no language restriction. All studies were required to meet the following inclusion criteria: 1) randomized controlled trials, 2) depressive patients, 3) at least 4 weeks of treatment, 4) SSRI-controlled, 5) available efficacy or safety indicators, and 6) outcome measures for depression or clinical diagnosis. Exclusion criteria were as follows: 1) lack of data on efficacy and safety, 2) combination with other antidepressants, and 3) single-blind and uncontrolled trials. Data from selected studies were extracted in tabular form, including basic information on the study, study design, study time, intervention measures, and specific outcomes.

\section{Measures of efficacy and safety}

The primary outcome measure for treatment efficacy and safety was change in total Hamilton Rating Scale for
Depression (HAMD) score between baseline and end point. Responder rates (reduction in HAMD score $>50 \%$ ), remission rate (reduction in HAMD score $>75 \%$ ), mean reduction in HAMD score, the incidence of adverse events, total withdrawal rate, and withdrawals due to adverse events were the key outcomes of interest.

\section{Formula conversion}

Some of the data in this study were not directly usable for statistical analysis, and therefore, converted into a form available for analysis. The main formulas used were 1) calculation of mean and standard deviation (SD) for change according to the known mean and SD before and after treatment: mean $(b-a)=$ mean $(b)-(a)$, variance $(b-a)=$ variance $(b)+$ variance $(a)$, taking the square root to obtain $\mathrm{SD}:(b-a)$ and 2) calculation of $\mathrm{SD}$ : $\left(\mathrm{CI}_{\max }-\mathrm{CI}_{\min }\right) /(1.96 \times 2)$ by using the confidence intervals.

\section{Statistical analysis}

All included studies were analyzed using Stata/SE (11.2) (StataCorp LP, College Station, TX, USA). For each metaanalysis, heterogeneity of treatment effects was tested before the data were pooled; if $P>0.05$ or $I^{2}<50 \%$, we considered the data to be homogeneous and used a fixed-effects model. Otherwise, we applied a random-effects model. Relative risk (RR) and 95\% confidence intervals $(95 \% \mathrm{CI})$ were calculated, and effect size (weighted mean difference) meta-analysis was performed. The event rate in the experimental (intervention) group against the event rate in the control group was calculated using the chi-square test, and the results were expressed as an odds ratio (OR) and $P$-values.

\section{Results}

A total of 27 articles were retrieved. ${ }^{11-15,17-24}$ The basic data of all studies are shown in Table 1 . A total of 3,126 patients were included in the analysis, with 1,177 patients from the People's Republic of China.

\section{Efficacy}

Summary RR for all included studies for clinical response was 1.02 (95\% CI: 0.96, 1.09, $P=0.51$, Figure 1). Furthermore, the combined summary RR of all studies for remission by St John's wort extract versus SSRIs therapy was 1.07 (95\% CI: 0.94, 1.22, $P=0.308$, Figure 2). Effect size (standard mean difference) for mean reduction in HAMD score from baseline with St John's wort extract versus SSRIs therapy among all the studies was -0.06 (95\% CI: $-0.13,0.02$, $P=0.15$, Figure 3 ). 


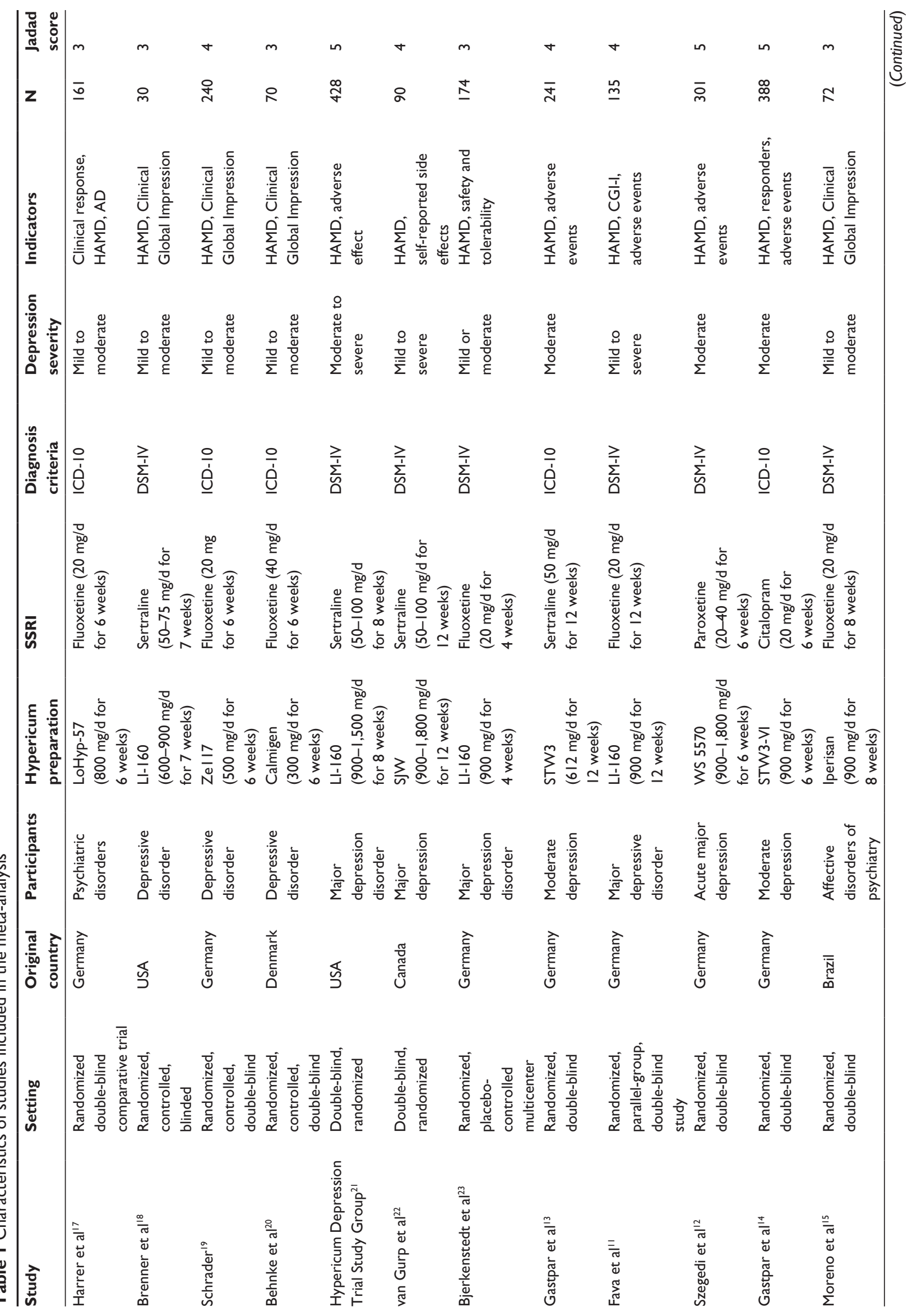




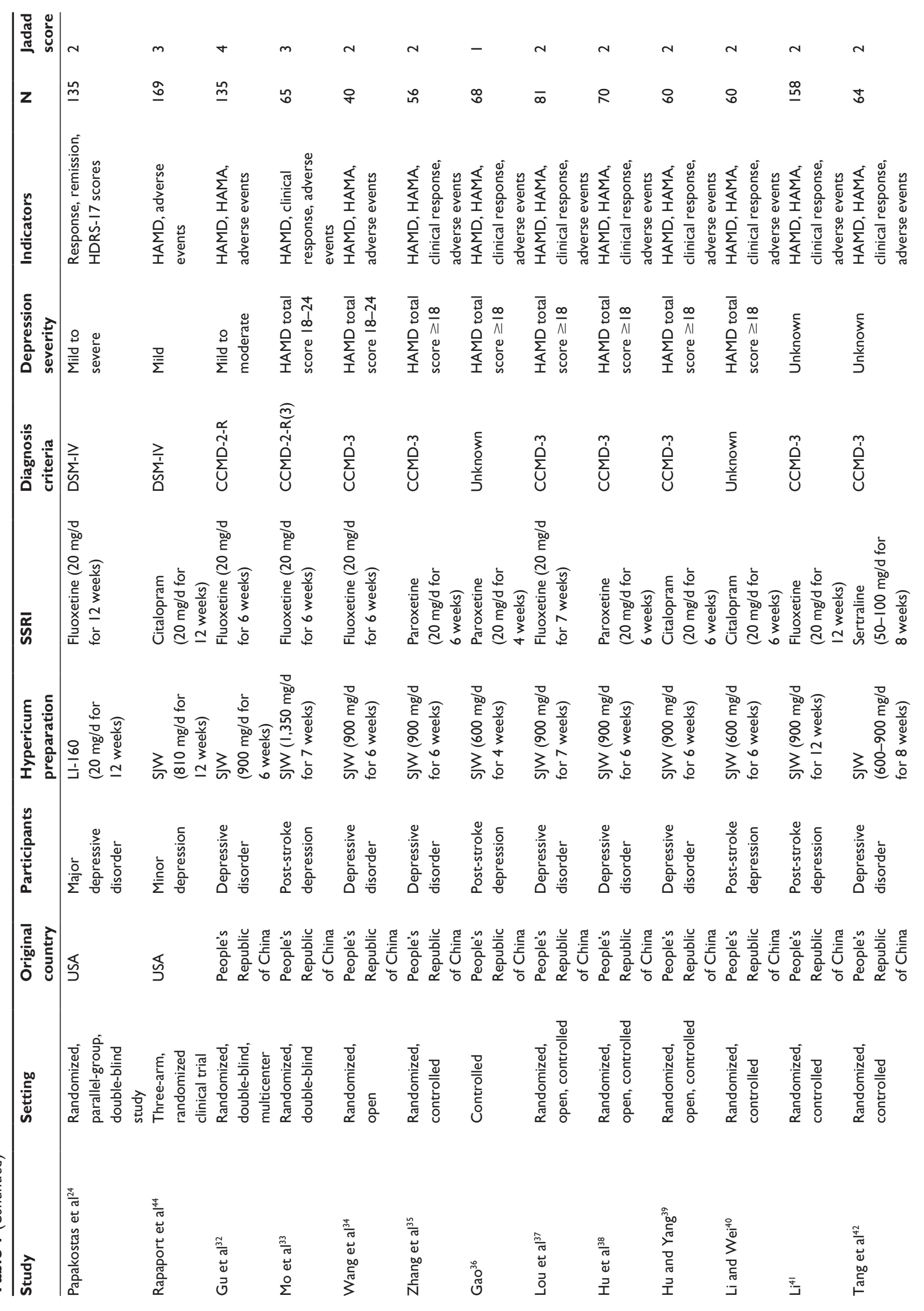




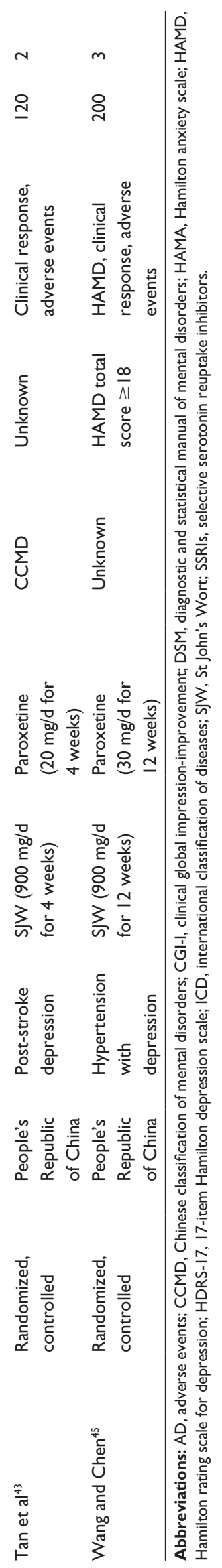

\section{Safety}

The number of patients reporting adverse events and withdrawal due to adverse events were evaluated in 19 and 12 trials, respectively. The summary RR for adverse events of St John's wort extract versus SSRI therapy among all included trials was 0.77 (95\% CI: $0.70,0.84, P=0.00$ ) (Figure 4). Twelve trials investigated withdrawals and withdrawal due to adverse events of St John's wort extract and SSRI therapy. The total withdrawal rate and withdrawal rate due to adverse events were $18.2 \%$ (167/916) and 4.1\% (38/916) in the St John's wort extract group, and 20.3\% (183/901) and 6.7\% (61/901) in the SSRI group, respectively. There was no significant difference in the total withdrawal rate of the two groups (chi-square test; $\mathrm{OR}=0.88,95 \% \mathrm{CI}$ : $0.69,1.11, P=0.28)$. Withdrawal due to adverse events in the St John's wort extract group was significantly less than that in the SSRI group (OR $=0.60,95 \%$ CI: $0.39,0.90, P=0.02$ ).

\section{Publication bias}

We did not observe a skewed distribution and the data substantially met a normal distribution, and the publication bias was also small.

\section{Sensitivity analysis}

We excluded trials one by one to perform sensitivity analysis. There was no significant difference between the statistical results before and after each exclusion, indicating that the study was stable and reliable.

\section{Discussion}

Although St John's wort extract has been used to treat depression for $>100$ years and its efficacy ${ }^{8-10}$ and safety ${ }^{11,12}$ have been proven in several clinical studies, its use in depression still remains somewhat controversial. A meta-analysis by Rahimi et a ${ }^{16}$ of 13 eligible randomized, placebo-controlled clinical trials published between 1966 and 2008 showed that St John's wort extract was comparable to SSRIs in efficacy and safety. Our current meta-analysis included additional studies as of 2008 with a total of 27 eligible studies and 3,126 depression patients. We found that consistent with the findings of Rahimi et al, ${ }^{16} \mathrm{St} \mathrm{John's} \mathrm{wort} \mathrm{extract} \mathrm{was} \mathrm{compa-}$ rable to SSRIs in efficacy, including clinical response, remission, and mean reduction in HAMD score. Unlike the study by Rahimi et al, ${ }^{16}$ we further demonstrated that St John's wort extract had a lower incidence of adverse events than SSRIs. These findings indicate that, compared to SSRIs, St John's wort extract is equally effective, but has superior safety in the management of depression patients. 


\begin{tabular}{|c|c|c|}
\hline Study ID & RR (95\% Cl) & $\%$ weight \\
\hline Gu et $\mathrm{al}^{32}$ & $1.24(0.99,1.56)$ & 5.46 \\
\hline Mo et $\mathrm{al}^{33}$ & $0.98(0.66,1.46)$ & 2.54 \\
\hline Wang et $\mathbf{a}^{34}$ & $1.07(0.76,1.49)$ & 1.93 \\
\hline Zhang et $a^{35}$ & $0.98(0.78,1.24)$ & 3.04 \\
\hline $\mathrm{GaO}^{36}$ & $1.04(0.78,1.39)$ & 3.14 \\
\hline Lou et $\mathrm{al}^{37}$ & $0.95(0.71,1.28)$ & 3.69 \\
\hline Hu et al ${ }^{38}$ & $0.96(0.72,1.28)$ & 3.35 \\
\hline $\mathrm{Hu}$ and $\mathrm{Yang}^{39}$ & $0.95(0.67,1.34)$ & 2.71 \\
\hline $\mathrm{Li}$ and $\mathrm{Wei}^{40}$ & $1.00(0.72,1.39)$ & 2.71 \\
\hline $\mathrm{Li}^{41}$ & $0.97(0.80,1.18)$ & 7.51 \\
\hline Tang et $\mathrm{al}^{42}$ & $1.21(0.73,2.02)$ & 1.81 \\
\hline Tan et $\mathbf{a l}^{43}$ & $0.93(0.64,1.35)$ & 3.87 \\
\hline Harrer et $\mathrm{al}^{17}$ & $0.99(0.81,1.21)$ & 6.91 \\
\hline Brenner et al ${ }^{18}$ & $1.17(0.51,2.66)$ & 0.77 \\
\hline Schrader ${ }^{19}$ & $1.51(1.15,1.97)$ & 6.10 \\
\hline Behnke et $\mathrm{al}^{20}$ & $0.76(0.49,1.20)$ & 2.71 \\
\hline Hypericum Depression Trial Study Group ${ }^{21}$ & $0.60(0.34,1.06)$ & 3.38 \\
\hline van Gurp et $\mathrm{al}^{22}$ & $0.91(0.58,1.42)$ & 2.84 \\
\hline Bjerkenstedt et al ${ }^{23}$ & $1.10(0.70,1.75)$ & 2.76 \\
\hline Gastpar et al ${ }^{13}$ & $0.94(0.80,1.10)$ & 11.32 \\
\hline Szegedi et $\mathrm{al}^{12}$ & $1.19(0.98,1.44)$ & 9.38 \\
\hline Gastpar et $a^{14}$ & $0.98(0.79,1.23)$ & 9.17 \\
\hline Moreno et al ${ }^{15}$ & $0.36(0.14,0.95)$ & 1.42 \\
\hline Rapaport et al ${ }^{44}$ & $0.93(0.49,1.79)$ & 1.47 \\
\hline Overall $\left(I^{2}=12.6 \%, P=0.286\right)$ & $1.02(0.96,1.09)$ & 100 \\
\hline $\begin{array}{c}1 \\
0.139\end{array}$ & $\begin{array}{c}1 \\
7.2\end{array}$ & \\
\hline
\end{tabular}

Figure I Pooled relative risk of the outcome of "clinical response" in the studies comparing St John's wort extract versus SSRIs therapy. Abbreviations: $\mathrm{Cl}$, confidence interval; $\mathrm{RR}$, relative risk; SSRIs, selective serotonin reuptake inhibitors.

\begin{tabular}{|c|c|c|c|}
\hline Study ID & & RR $(95 \% \mathrm{Cl})$ & $\%$ weight \\
\hline Gu et $\mathrm{al}^{32}$ & & $1.24(0.81,1.91)$ & 8.09 \\
\hline Mo et $\mathrm{al}^{33}$ & & $1.03(0.28,3.78)$ & 1.37 \\
\hline Wang et $\mathrm{al}^{34}$ & & $0.89(0.43,1.83)$ & 3.14 \\
\hline Zhang et $\mathrm{al}^{35}$ & & $1.01(0.57,1.78)$ & 4.49 \\
\hline $\mathrm{Gao}^{36}$ & & $1.11(0.50,2.47)$ & 2.96 \\
\hline Lou et $\mathrm{al}^{37}$ & & $1.13(0.54,2.36)$ & 3.45 \\
\hline Hu et $\mathrm{al}^{38}$ & & $1.07(0.63,1.80)$ & 5.24 \\
\hline Hu and Yang ${ }^{39}$ & & $0.93(0.55,1.58)$ & 5.24 \\
\hline $\mathrm{Li}$ and $\mathrm{Wei}^{40}$ & & $1.11(0.53,2.34)$ & 3.14 \\
\hline $\mathrm{Li}^{41}$ & & $0.95(0.70,1.30)$ & 14.13 \\
\hline Tang et $\mathrm{al}^{42}$ & & $1.29(0.55,3.03)$ & 2.44 \\
\hline Tan et $\mathrm{al}^{43}$ & & $0.91(0.42,1.98)$ & 3.84 \\
\hline Hypericum Depression Trial Study Group ${ }^{21}$ & & $0.98(0.62,1.56)$ & 9.51 \\
\hline Bjerkenstedt et $\mathrm{al}^{23}$ & 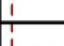 & $0.84(0.44,1.60)$ & 5.33 \\
\hline Fava et al ${ }^{11}$ & & $1.27(0.71,2.26)$ & 4.78 \\
\hline Szegedi et al ${ }^{12}$ & & $1.43(1.06,1.93)$ & 14.95 \\
\hline Moreno et $\mathrm{al}^{15}$ & & $0.43(0.13,1.43)$ & 2.44 \\
\hline Papakostas et al ${ }^{24}$ & & $0.85(0.46,1.56)$ & 5.46 \\
\hline Overall $\left(I^{2}=0.0 \%, P=0.930\right)$ & & $1.07(0.94,1.22)$ & 100 \\
\hline $\begin{array}{c}1 \\
0.129\end{array}$ & 1 & $\begin{array}{c}1 \\
7.76\end{array}$ & \\
\hline
\end{tabular}

Figure 2 Pooled relative risk of the outcome of "remission" in the studies comparing St John's wort extract versus SSRI therapy. Abbreviations: $\mathrm{Cl}$, confidence interval; RR, relative risk; SSRIs, selective serotonin reuptake inhibitors. 


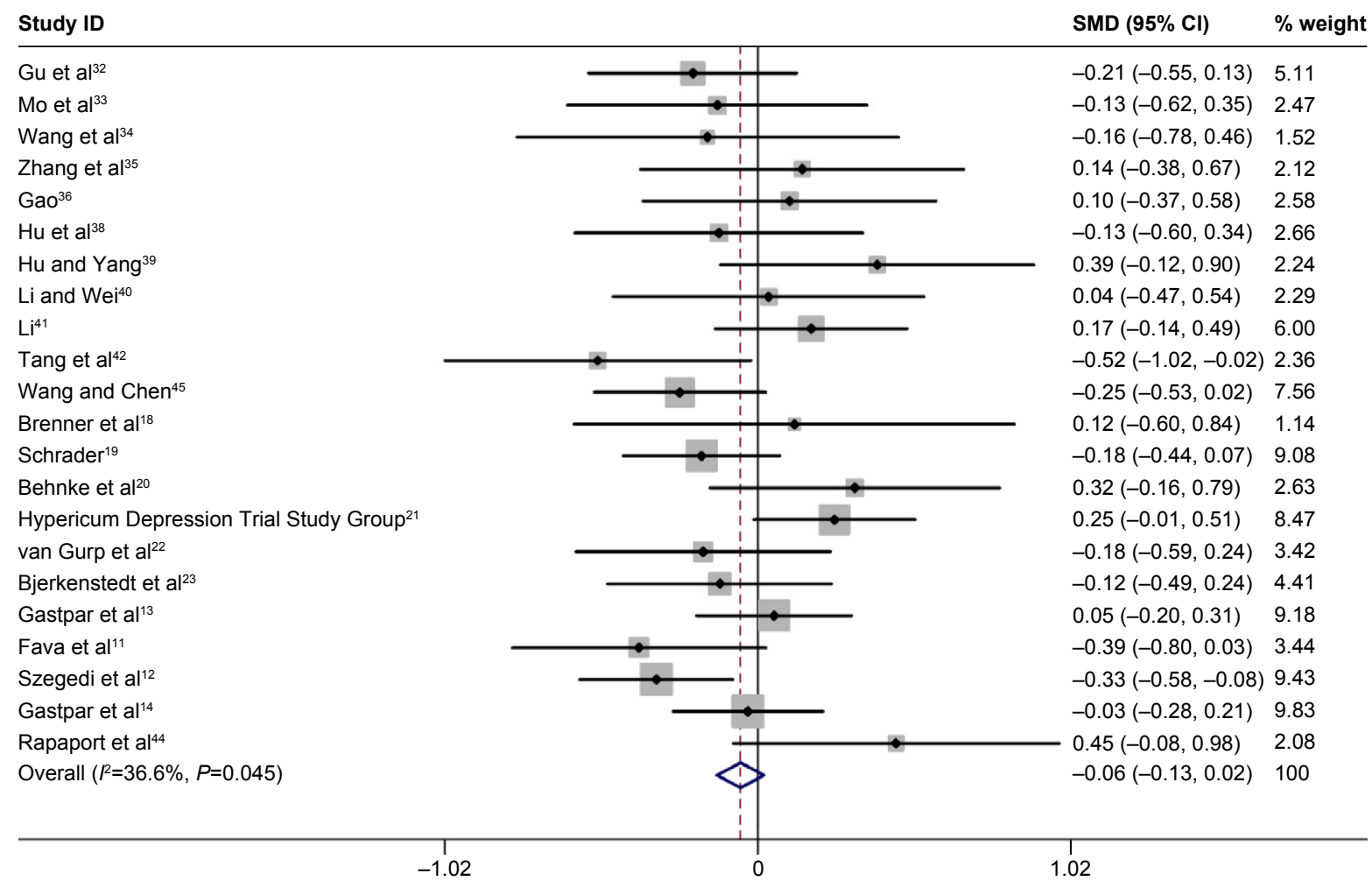

Figure 3 Pooled standard mean difference for the outcome of "mean reduction in HAMD score from baseline" in the studies comparing St John's wort extract versus SSRI therapy.

Abbreviations: $\mathrm{Cl}$, confidence interval; HAMD, Hamilton Rating Scale for Depression; SMD, standard mean difference; SSRIs, selective serotonin reuptake inhibitors.

\begin{tabular}{|c|c|c|}
\hline Study ID & $\mathrm{RR}(95 \% \mathrm{Cl})$ & $\%$ weight \\
\hline Gu et al ${ }^{32}$ & $0.69(0.45,1.04)$ & 5.96 \\
\hline Mo et al ${ }^{33}$ & $0.52(0.10,2.62)$ & 0.71 \\
\hline Wang et al ${ }^{34}$ & $0.75(0.41,1.37)$ & 2.15 \\
\hline Zhang et $a^{35}$ & $0.56(0.29,1.07)$ & 2.69 \\
\hline $\mathrm{Gao}^{36}$ & $0.15(0.02,1.17)$ & 1.14 \\
\hline Lou et $\mathrm{a}^{37}$ & $0.84(0.54,1.31)$ & 3.90 \\
\hline Hu et $a^{38}$ & $0.57(0.27,1.19)$ & 2.51 \\
\hline $\mathrm{Hu}$ and $\mathrm{Yang}^{39}$ & $0.64(0.29,1.42)$ & 1.97 \\
\hline $\mathrm{Li}$ and $\mathrm{Wei}^{40}$ & $0.91(0.46,1.81)$ & 1.97 \\
\hline Wang and $\mathrm{Chen}^{45}$ & $0.61(0.45,0.83)$ & 10.58 \\
\hline Harrer et al ${ }^{17}$ & $0.80(0.41,1.55)$ & 2.86 \\
\hline Schrader ${ }^{19}$ & $0.55(0.32,0.95)$ & 5.27 \\
\hline Behnke et $\mathrm{al}^{20}$ & $1.10(0.75,1.61)$ & 3.59 \\
\hline van Gurp et $\mathrm{al}^{22}$ & $1.16(0.83,1.63)$ & 4.48 \\
\hline Bjerkenstedt et $a^{23}$ & $0.71(0.57,0.87)$ & 9.48 \\
\hline Gastpar et al ${ }^{13}$ & $1.18(0.94,1.49)$ & 10.98 \\
\hline Szegedi et al ${ }^{12}$ & $0.72(0.60,0.87)$ & 17.14 \\
\hline Gastpar et al ${ }^{14}$ & $0.71(0.51,1.00)$ & 9.65 \\
\hline Rapaport et al ${ }^{44}$ & $0.58(0.32,1.05)$ & 2.97 \\
\hline Overall $\left(I^{2}=46.3 \%, P=0.015\right)$ & $0.77(0.70,0.84)$ & 100 \\
\hline $\begin{array}{c}1 \\
0.0188\end{array}$ & $\begin{array}{c}1 \\
53.1\end{array}$ & \\
\hline
\end{tabular}

Figure 4 Pooled relative risk of the outcome of "adverse events" in the studies comparing St John's wort extract versus SSRI therapy. Abbreviations: $\mathrm{Cl}$, confidence interval; $\mathrm{RR}$, relative risk; SSRIs, selective serotonin reuptake inhibitors. 
St John's wort extract is currently the only pure plant antidepressant and is especially suitable for mild-to-moderate depression. It competitively inhibits absorption of serotonin, noradrenaline, and dopamine; it also downregulates presynaptic membrane-adrenergic receptor density and reduces binding of neurotransmitters to presynaptic membrane-adrenergic receptors, thereby increasing their concentrations in the synaptic cleft, mimicking the effect of antidepressants. ${ }^{25,26}$ Studies have shown that St John's wort extract is superior to placebo $^{8-10}$ and comparable to SSRIs ${ }^{27}$ in efficacy. St John's wort causes mild adverse effects such as occasional dry mouth and constipation, and it causes no memory impairment, an apparent advantage for older patients. ${ }^{28}$ Our study demonstrates significantly lower rates of adverse events in depression patients receiving St John's wort extract versus SSRIs, and consistent with the study by Rahimi et al, ${ }^{16}$ markedly lower rates of withdrawal due to adverse events.

One limitation of the current meta-analysis is the lack of data on treatment of adolescents with depression. Depression is a significant disease for adolescents. Little literature has been published on adolescent depression. All studies included in our meta-analysis involve only adult patients with depression. A small number of studies have shown that St John's wort extract is superior to placebo in treating teenagers with moderate and severe depression; ${ }^{29,30}$ however, a definite conclusion awaits the results of randomized controlled trials involving a larger population of adolescents with depression. Depression is a chronic disease requiring long-term medication therapy, incurring a financial burden on the patients. It is also important to investigate cost-effectiveness of St John's wort extract versus SSRIs, which was not addressed in our meta-analysis. Solomon et $\mathrm{al}^{31}$ investigated the economic cost of St John's wort extract for mild-to-moderate depression using Markov model and found that St John's wort extract markedly reduced medication costs compared with SSRIs.

\section{Conclusion}

Although St John's wort has been used as a herbal remedy for depression for many years, especially in Germany and other European countries, its efficacy is still controversial. Our meta-analysis analyzed 27 studies and 3,126 depression patients and so far represents the most comprehensive analysis of clinical studies on St John's wort for depression. Although this study did not explore neurobiological mechanisms of St John's wort, our results are consistent with the hypothesis that St John's wort is an effective therapy for depression. Furthermore, our analysis demonstrates that in the treatment of depression, especially mild-to-moderate depression, St John's wort extract has comparable efficacy to SSRIs, while the rate of adverse events and withdrawals is significantly lower than that of traditional SSRIs. Given the low cost of treatment with St John's wort extract versus SSRIs, its significant efficacy, and good safety profile, St John's wort extract may be a preferred therapeutic choice in the management of depression.

\section{Acknowledgment}

This study was funded by the Beijing Municipal Administration of Hospitals Clinical Medicine Development of Special Funding Support (code: ZYLX 201403).

\section{Disclosure}

The authors report no conflicts of interest in this work.

\section{References}

1. Phillips MR, Zhang J, Shi Q, et al. Prevalence, treatment, and associated disability of mental disorders in four provinces in China during 2001-05: an epidemiological survey. Lancet. 2009;373(9680):2041-2053.

2. Regier DA, Boyd JH, Burke JD Jr, et al. One-month prevalence of mental disorders in the United States: based on five Epidemiologic Catchment Area sites. Arch Gen Psychiatry. 1988;45(11):977-986.

3. Wittchen HU, Jacobi F. Size and burden of mental disorders in Europe - a critical review and appraisal of 27 studies. Eur Neuropsychopharmacol. 2005;15(4):357-376.

4. Hansen RA, Gartlehner G, Lohr KN, Gaynes BN, Carey TS. Efficacy and safety of second-generation antidepressants in the treatment of major depressive disorder. Ann Intern Med. 2005;143(6):415-426.

5. Cascade E, Kalali AH, Kennedy SH. Real-world data on SSRI antidepressant side effects. Psychiatry (Edgmont). 2009;6(2):16-18.

6. Bukhari I, Dar A. Behavioral profile of Hypericum perforatum (St. John's Wort) extract. A comparison with standard antidepressants in animal models of depression. Eur Rev Med Pharmacol Sci. 2013; 17(8):1082-1089.

7. Kasper S, Gastpar M, Möller H-J, et al. Better tolerability of St. John's wort extract WS 5570 compared to treatment with SSRIs: a reanalysis of data from controlled clinical trials in acute major depression. Int Clin Psychopharmacol. 2010;25(4):204-213.

8. Kalb R, Trautmann-Sponsel R, Kieser M. Efficacy and tolerability of hypericum extract WS 5572 versus placebo in mildly to moderately depressed patients. A randomized double-blind multicenter clinical trial. Pharmacopsychiatry. 2001;34(3):96-103.

9. Kasper S, Anghelescu IG, Szegedi A, Dienel A, Kieser M. Superior efficacy of St John's wort extract WS ${ }^{\circledR} 5570$ compared to placebo in patients with major depression: a randomized, double-blind, placebo-controlled, multi-center trial [ISRCTN77277298]. BMC Med. 2006;4(1):14.

10. Lecrubier Y, Clerc G, Didi R, Kieser M. Efficacy of St. John's wort extract WS 5570 in major depression: a double-blind, placebo-controlled trial (Abstracts). Am J Psychiatry. 2002;159(8):1361-1366.

11. Fava M, Alpert J, Nierenberg AA, et al. A double-blind, randomized trial of St John's wort, fluoxetine, and placebo in major depressive disorder. J Clin Psychopharmacol. 2005;25(5):441-447.

12. Szegedi A, Kohnen R, Dienel A, Kieser M. Acute treatment of moderate to severe depression with hypericum extract WS 5570 (St John's wort): randomised controlled double blind non-inferiority trial versus paroxetine. BMJ. 2005;330(7490):503.

13. Gastpar M, Singer A, Zeller K. Efficacy and tolerability of hypericum extract STW3 in long-term treatment with a once-daily dosage in comparison with sertraline. Pharmacopsychiatry. 2005;38(2):78-86. 
14. Gastpar M, Singer A, Zeller K. Comparative efficacy and safety of a oncedaily dosage of hypericum extract STW3-VI and citalopram in patients with moderate depression: a double-blind, randomised, multicentre, placebo-controlled study. Pharmacopsychiatry. 2006;39(2):66-75.

15. Moreno RA, Teng CT, Almeida KM, Tavares Junior H. Hypericum perforatum versus fluoxetine in the treatment of mild to moderate depression: a randomized double-blind trial in a Brazilian sample. Rev Bras Psiquiatr. 2006;28(1):29-32.

16. Rahimi R, Nikfar S, Abdollahi M. Efficacy and tolerability of Hypericum perforatum in major depressive disorder in comparison with selective serotonin reuptake inhibitors: a meta-analysis. Prog Neuropsychopharmacol Biol Psychiatry. 2009;33(1):118-127.

17. Harrer G, Schmidt U, Kuhn U, Biller A. Comparison of equivalence between the St. John's wort extract LoHyp-57 and fluoxetine. Arzneimittelforschung. 1999;49(4):289-296.

18. Brenner R, Azbel V, Madhusoodanan S, Pawlowska M. Comparison of an extract of hypericum (LI 160) and sertraline in the treatment of depression: a double-blind, randomized pilot study. Clin Ther. 2000;22(4): 411-419.

19. Schrader E. Equivalence of St John's wort extract (Ze 117) and fluoxetine: a randomized, controlled study in mildmoderate depression. Int Clin Psychopharmacol. 2000;15(2):61-68.

20. Behnke K, Jensen GS, Graubaum HJ, Gruenwald J. Hypericum perforatum versus fluoxetine in the treatment of mild to moderate depression. Adv Ther. 2002;19(1):43-52.

21. Hypericum Depression Trial Study Group. Effect of Hypericum perforatum (St John's wort) in major depressive disorder: a randomized controlled trial. JAMA. 2002;287(14):1807-1814.

22. van Gurp G, Meterissian GB, Haiek LN, McCusker J, Bellavance F. St John's wort or sertraline? Randomized controlled trial in primary care. Can Fam Physician. 2002;48(5):905-912.

23. Bjerkenstedt L, Edman GV, Alken RG, Mannel M. Hypericum extract LI 160 and fluoxetine in mild to moderate depression. Eur Arch Psychiatry Clin Neurosci. 2005;255(1):40-47.

24. Papakostas GI, Crawford CM, Scalia MJ, Fava M. Timing of clinical improvement and symptom resolution in the treatment of major depressive disorder. A replication of findings with the use of a double-blind, placebo-controlled trial of Hypericum perforatum versusfluoxetine. Neuropsychobiology. 2007;56(2-3):132-137.

25. Rommelspacher H, Siemanowitz B, Mannel M. Acute and chronic actions of a dry methanolic extract of Hypericum perforatum and a hyperforin-rich extract on dopaminergic and serotonergic neurones in rat nucleus accumbens. Pharmacopsychiatry. 2001;34(Suppl 1): S119-S126.

26. Trivedi $\mathrm{MH}$, Claassen CA, Grannemann BD, et al. Assessing physicians' use of treatment algorithms: Project IMPACTS study design and rationale. Contemp Clin Trials. 2007;28(2):192-212.

27. Bennett DA Jr, Phun L, Polk JF, Voglino SA, Zlotnik V, Raffa RB. Neuropharmacology of St. John's wort (hypericum). Ann Pharmacother. 1998;32(11):1201-1208.
28. Wang YS, Li YL, Yan GQ, et al. Clinical study of neurostan in treatment of encephalosis secondary depression. Chin J Pract Nerv Dis. 2009; (21):84-85.

29. Findling RL, McNamara NK, O'Riordan MA, et al. An open-label pilot study of St. John's wort in juvenile depression. J Am Acad Child Adolesc Psychiatry. 2003;42(8):908-914.

30. Simeon J, Nixon MK, Milin R, Jovanovic R, Walker S. Open-label pilot study of St. John's wort in adolescent depression. J Child Adolesc Psychopharmacol. 2005;15(2):293-301.

31. Solomon D, Adams J, Graves N. Economic evaluation of St. John's wort (Hypericum perforatum) for the treatment of mild to moderate depression. J Affect Disord. 2013;148(2-3):228-234.

32. Gu N, Li H, Shu L, Zhang H. Multicenter study of St. John's wort extract in treatment of mild to moderate depression. Chin J Clin Pharm. 2001; $10: 271-274$

33. Mo W-Y, Yu H-Y, Yang Y. Comparison of San John'Wort extract with fluoxetine in the treatment of post-stroke depression. Chin New Drugs J. 2004;13:942-944.

34. Wang $\mathrm{M}, \mathrm{Hu} \mathrm{J}$, Zhao L. Control study of neurostan and fluoxetine in treatment of patients with depression. J Clin Psychol Med. 2005; 15(5):287.

35. Zhang XY, Wang ZW, Cai QQ. Control study of neurostan and paroxetine in treatment of patients with depression. J Clin Psychol Med. 2006;(3):173-174.

36. Gao CY. Efficacy of neurostan in the treatment of post-stroke depression. Chin J Pract Nerv Dis. 2006;(2):65-66.

37. Lou SQ, Yang GS, Qian DL. Study of St John's wort in treatment of patients with depression. Chin Hosp Pharm J. 2006;(12):1525-1526.

38. Hu JY, Yang LJ, Wu XH, Liao N. Control study of neurostan and paroxetine in treatment of patients with senile depression. Med J Chin People Health. 2008;(9):884-885.

39. Hu JY, Yang LJ. Study of neurostan and citalopram in treatment of patients with depression. Sichuan MentHealth. 2008;(4):227-228.

40. Li QB, Wei HR. Comparison of neurostan with citalopram in the treatment of post-stroke depression. J Mod Med Health. 2009;(18): 2789-2790.

41. Li M. Efficacy of St John's Wort extract in the treatment of post-stroke depression. Hebei Med J. 2011;(19):2961-2962.

42. Tang K, Ye QH, Liu SJ, Chen ZB. Study of neurostan and Sertraline in treatment of elder patients with depression. Guid J Tradit Chin Med Pharm. 2012;(2):40-42.

43. Tan XW, Wang XL, Zhao Y. Study of neurostan in the treatment of post-stroke depression. Chin J Mod Drug Appl. 2014;(23):89-90.

44. Rapaport MH, Nierenberg AA, Howland R, Dording C, Schettler PJ, Mischoulon D. The treatment of minor depression with St. John's Wort or citalopram: failure to show benefit over placebo. J Psychiatr Res. 2011; 45(7):931-941.

45. Wang Y, Chen JP. Comparison the efficacy of St. John's Wort with paroxetine combined with antihypertensive drug in the treatment of depression with hypertension. Chin J Rural Med Pharm. 2014;(3):12-13.
Neuropsychiatric Disease and Treatment

\section{Publish your work in this journal}

Neuropsychiatric Disease and Treatment is an international, peerreviewed journal of clinical therapeutics and pharmacology focusing on concise rapid reporting of clinical or pre-clinical studies on a range of neuropsychiatric and neurological disorders. This journa is indexed on PubMed Central, the 'PsycINFO' database and CAS,

\section{Dovepress}

and is the official journal of The International Neuropsychiatric Association (INA). The manuscript management system is completely online and includes a very quick and fair peer-review system, which is all easy to use. Visit http://www.dovepress.com/testimonials.php to read real quotes from published authors. 